\title{
Minimum Quantity Lubricant: A Beneficial Application in Hard-Milling of AISI H13 Steel
}

\author{
Quang-Cherng Hsu ${ }^{1}$, The-Vinh Do ${ }^{2, *}$, Thi-Nguyen Nguyen $^{2}$ \\ ${ }^{1}$ National Kaohsiung University of Science and Technology, Taiwan \\ ${ }^{2}$ Thai Nguyen University of Technology, Vietnam
}

Received October 16, 2019; Revised November 15, 2019; Accepted November 19, 2019

Copyright $\odot 2019$ by authors, all rights reserved. Authors agree that this article remains permanently open access under the terms of the Creative Commons Attribution License 4.0 International License

\begin{abstract}
In this study, the efficiency of minimum quantity lubricant (MQL) was demonstrated during hard-milling of AISI H13 steel with a carbide-coated (TiAlN) cutting tool. A comparative analysis was done to prove the effectiveness of MQL versus the dry cutting method based on certain process parameters such as surface roughness and cutting force. The L27 orthogonal array of the Taguchi method was used for designing the experiment. An analysis of the influence of cutting parameters including cutting-speed, feed-rate, depth-of-cut and hardness-of-workpiece on the cutting force and the surface roughness was carried out by using the response surface methodology (RSM) and analysis of variance (ANOVA). The result shows that under both of the cutting conditions (MQL and dry), feed rate and depth-of-cut are main factors affecting surface roughness and cutting force. Further, quadratic mathematical models for predicting cutting force and surface roughness under dry cutting and MQL conditions were established. The analysis of the roughness and the cutting force showed the outstanding effectiveness of MQL when compared with dry cutting.
\end{abstract}

Keywords MQL, Hard-Milling, Dry Cutting, Cutting Force, Surface Roughness, RSM

\section{Introduction}

"Why perform dry cutting?" This question has been answered in numerous studies and during actual production. In their research, Sreejith, et al. [1] remarked that dry cutting is the machining method of the future. The appearance of CAD/CAM (Computer-aided design/ Computer-aided manufacturing) systems, the significant advances of manufacturing, coating techniques for cutting tools, and the industrial development of cutting machines have all changed the metal-cutting process entirely. The application of fluid cutting (or wet cutting) in traditional metal machining has decreased of late due to the environmental and human health concerns it causes. In fluid cutting, a lubricant or cutting fluid is applied in order to improve the tribological processes that occur between the surfaces of the cutting tool and the workpiece. The immediate advantages of using a cutting fluid during the machining process are an improvement in surface roughness, an increase in tool life, a reduction of tool wear, and a lowered cutting temperature [2-5]. However, the fluid cutting method has many negative effects, especially with the significant adverse environmental effects it causes and possible damage to operators' health [1-4, 6]. Any reduction, or even elimination, of the use of cutting fluids involved during machining would be seen as a major incentive to switch to a non-cutting-fluid method. Therefore, dry cutting is presented as both an efficient and a desirable alternative to fluid cutting. The advantages of dry cutting include non-polluting of the environment, a reduction in manufacturing cost through a saving in coolant-related cost and lowered cleaning costs, and no further danger to health of operators due to prohibitive contact with toxic cutting fluid substances [1, 2, 4, 7]. In cases of interrupted cutting, dry cutting improves tool life due to an avoidance of thermal shock to the tool [1]. In some cases, the required cutting forces using dry cutting is lower than what occurs under wet cutting due to the effect of increased cutting temperature and a thermal softening of the materials [8].

The aim of the current study is to offer an analysis of effective hard machining under different conditions. Hard-machining is a term used to describe the machining process of steel with a 40-60 HRC hardness with many improvements $[9,10]$. The machined surface of hard machining is the same as in the grinding process whenever suitable cutting parameters are to be applied [10]. Further, utilizing hard machining can reduce manufacturing costs, has higher material removal rates, 
and decrease machining time. Flexible process design is also a distinct advantage of hard machining [11, 12]. Nevertheless, hard machining under dry conditions also has disadvantages because of increased tool wear, and reduced tool life due to the effect of contact with ultra-hard materials [12, 13]. The application of flood coolant in hard-milling is not recommended due to the reasons mentioned above.

MQL is an acronym used to represent a procedure in which a very small amount of cutting fluid less than 50 $\mathrm{ml} / \mathrm{h}$ is pulverized in a flow of air directed at the cutting zone during the machining process [3]. MQL has been widely applied in the machining processes such as milling, turning and drilling by its efficiency and environmental issues. MQL machining has many advantages such as the improvement of surface roughness [7, 14-16], reduction of tool wear, enhancement of tool life, decrease in cutting temperature, and a reduction in lubricant-related costs [7, 14, 16-20]. The benefits of using MQL in comparison to dry cutting and wet cutting methods have been proved in many studies. In a study of Dhar, et al. [14], the influence of MQL on tool wear and surface roughness during turning AISI-4340 steel was recorded. There was a significant reduction in tool wear and improvement of surface roughness by MQL because of a reduction of temperature in the cutting zone and a favorable change in the chip-tool and work-tool interaction. In other research, the effects of MQL using vegetable oil-based cutting fluid were significant when compared with wet and dry cutting [16]. A decrease of cutting temperature, a reduction of tool wear, and a minimum of surface roughness were presented by using MQL in turning AISI 9310 alloy steel. Similarly, in another research, Dhar, et al. [17] reported a reduction of cutting temperature in turning AISI-1040 steel by employing MQL. In the milling process, the contributions of MQL have been also recorded in many other studies. In the research of Kang, et al. [18], and Iqbal, et al. [19] the tool life was enhanced by applying MQL in high-speed end milling. In the milling of Inconel 718 steel [21], Thamizhmanii et al. concluded that surface roughness obtained by using MQL is improved rather than by dry cutting. The tool life was higher by $43.75 \%$ by MQL rather than by dry cutting. In research of Rahman, et al. [22], a conclusion shown is that the surface roughness obtained by MQL is equivalent to what was obtained through wet cutting means. The difference in cutting force between that of flood cooling and MQL was considered to be insignificant.

Because of its considerable resistance to thermal softening, appreciable toughness, high hardenability and high resistance to abrasion, AISI H13 is used widely in manufacturing, especially in high-pressure die casting and extrusion molding, cutting blades, and hot dies. The hardness of AISI H13 is recommended to be at 40-50 HRC in its application for mold and die manufacturing. Hence, AISI H13 has been the subject of many types of research related to the machining process. Ding, et al. [9] performed an experimental investigation into the establishment of two empirical models used for determining the cutting force and surface roughness in the hard-milling of AISI H13 steel with carbide-coated tools. The effect of cutting parameters on cutting forces and surface roughness was analyzed by using Taguchi method and ANOVA. The results of research expressed that depth-of-cut is the main factor affecting surface roughness and cutting force. In a study by Ozel, et al. [23], an investigation into the effects of cutting edge geometry, workpiece-hardness, feed-rate and cutting-speed on surface roughness and cutting force in the finished hard-turning of AISI H13 steel was carried out. The results showed that honed-edge geometry and lower workpiece surface hardness lead to good surface roughness. The lower workpiece surface-hardness and honed-edge geometry lead to lower tangential and radial forces. Ghani, et al. [24] used Taguchi method to investigate the effects of cutting parameters on surface roughness and cutting force in the milling process. The result showed that high cutting-speed, low feed-rate and lower depth-of-cut lead to better surface roughness and lower-cutting force. Similarly, in hard-milling of JIS SKD61 alloy steel (AISI H13), Nguyen, et al. [25] concluded that high cutting-speed, low feed-rate, low depth-of-cut, and low hardness resulted in good surface roughness.

The application of MQL in hard-milling of AISI H13 steel has not been adequately studied to date. Therefore, we are motivated to respond to the question of "Why use MQL cutting?” In this research, an attempt has been made to demonstrate the efficiency of MQL compared with dry cutting in the hard-milling of AISI H13 steel. The surface roughness and cutting force were obtained in a series of meticulous experiments. The L27 orthogonal array of the Taguchi method was used for designing the experiment. The second-order mathematical models for predicting the surface roughness and the cutting force under MQL and dry cutting were established by using RSM. The analysis expressed the outstanding effectiveness of MQL when compared with dry cutting.

\section{Experiment Details}

The L27 array of the Taguchi method was applied for designing the experiment. The input factors are cutting parameters including cutting-speed $(v)$, feed-rate $(f)$, depth-of-cut $(d)$ and hardness-of-workpiece $(h)$. The relationship between cutting parameters and surface roughness, cutting force was investigated under dry cutting and MQL cutting conditions. Each parameter has three levels (represented by 1, 2, and 3). The cutting parameters were selected within the recommended settings of the cutting tool manufacture based on 
workpiece material, hardness-of-workpiece, and cutting tool employed. The variable levels were chosen with consideration to the tool life, cutting productivity, and surface roughness. The input factors with levels are shown in Table 1.

The hard-milling processes of AISI H13 steel were carried out under two different conditions given as dry machining and MQL utilizing a Victor V-Center-4 vertical machining center. The $\phi 10$ TiAlN coated-end mill cutting tools with 4 flutes, rake angle of $12^{\circ}$, and helix angle of $35^{\circ}$ were used in the experiments. The $\mathrm{Sj}-401$ surf-test instrument was used to measure the surface roughness. The cutting force was measured utilizing a piezo-electric, three-component dynamometer (type XYZ FORCE SENSOR, model 624-120-5KN) and a System 6000 - Model 6100 scanner. The signal is analyzed by means of Strain Smart force measurement software. Table 2 shows the information regarding the MQL as it is applied in the experiment [26]. Each experiment was repeated five times to eliminate experimental error occurring. The experimental set-up is illustrated in Figure 1 .

Table 1. Cutting parameters with levels

\begin{tabular}{|c|c|c|c|c|}
\hline \multirow{2}{*}{ Levels } & \multicolumn{4}{|c|}{ Cutting parameters } \\
\cline { 2 - 5 } & $\boldsymbol{v}(\mathbf{m} / \mathbf{m i n})$ & $\boldsymbol{f ( m m / t o o t h )}$ & $\boldsymbol{d}(\mathbf{m m})$ & $\boldsymbol{h}$ (HRC) \\
\hline 1 & 40 & 0.01 & 0.2 & 40 \\
\hline 2 & 55 & 0.02 & 0.4 & 45 \\
\hline 3 & 70 & 0.03 & 0.6 & 50 \\
\hline
\end{tabular}

Table 2. Information about the MQL process

\begin{tabular}{|c|c|}
\hline Items & Description \\
\hline MQL spray & Noga - MC 1700 \\
\hline Fluid flow $(\mathrm{ml} / \mathrm{h})$ & 50 \\
\hline Pressure $(\mathrm{kg} / \mathrm{cm} 2)$ & 3 \\
\hline Lubricant & Water-soluble oil \\
\hline
\end{tabular}

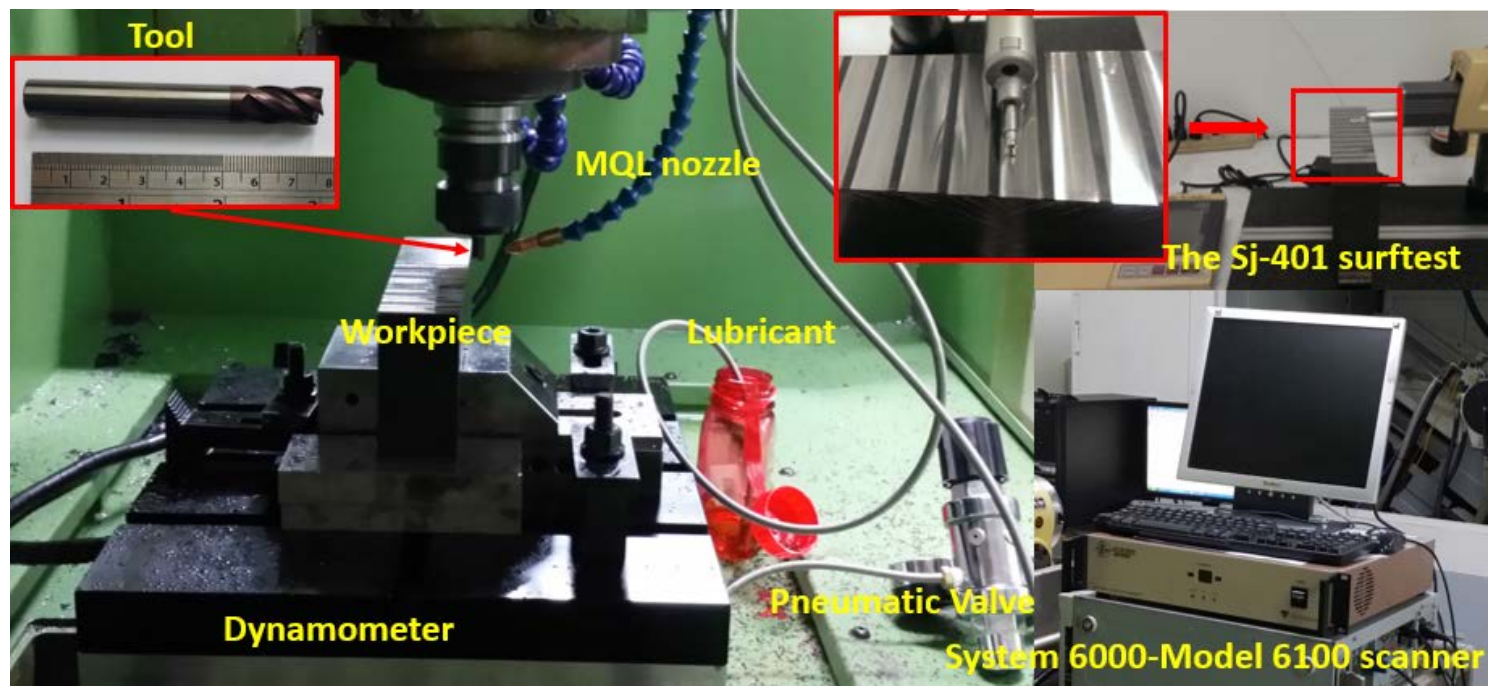

Figure 1. The experimental setup 
Table 3. Experimental results for surface roughness and cutting force components

\begin{tabular}{|c|c|c|c|c|c|c|c|c|}
\hline Exp.No. & $v$ & $f$ & $d$ & $\boldsymbol{h}$ & $\begin{array}{c}\text { Ra-mqI } \\
(\mu \mathrm{m})\end{array}$ & $\begin{array}{c}F-m q l \\
(\mathrm{~N})\end{array}$ & $\begin{array}{c}\text { Ra-dry } \\
(\mu \mathrm{m})\end{array}$ & $\begin{array}{l}\text { F-dry } \\
\text { (N) }\end{array}$ \\
\hline 1 & 1 & 1 & 1 & 1 & 0.151 & 61.665 & 0.161 & 65.189 \\
\hline 2 & 1 & 1 & 2 & 2 & 0.202 & 162.458 & 0.233 & 167.712 \\
\hline 3 & 1 & 1 & 3 & 3 & 0.285 & 248.328 & 0.329 & 238.332 \\
\hline 4 & 1 & 2 & 1 & 2 & 0.181 & 110.399 & 0.216 & 115.756 \\
\hline 5 & 1 & 2 & 2 & 3 & 0.221 & 250.773 & 0.258 & 245.125 \\
\hline 6 & 1 & 2 & 3 & 1 & 0.308 & 276.990 & 0.362 & 273.768 \\
\hline 7 & 1 & 3 & 1 & 3 & 0.251 & 162.954 & 0.301 & 168.613 \\
\hline 8 & 1 & 3 & 2 & 1 & 0.273 & 204.039 & 0.334 & 205.969 \\
\hline 9 & 1 & 3 & 3 & 2 & 0.405 & 345.691 & 0.496 & 353.838 \\
\hline 10 & 2 & 1 & 1 & 2 & 0.142 & 69.083 & 0.154 & 72.451 \\
\hline 11 & 2 & 1 & 2 & 3 & 0.209 & 165.953 & 0.238 & 171.498 \\
\hline 12 & 2 & 1 & 3 & 1 & 0.163 & 180.343 & 0.19 & 185.041 \\
\hline 13 & 2 & 2 & 1 & 3 & 0.239 & 104.320 & 0.29 & 107.281 \\
\hline 14 & 2 & 2 & 2 & 1 & 0.207 & 163.487 & 0.24 & 163.868 \\
\hline 15 & 2 & 2 & 3 & 2 & 0.254 & 235.075 & 0.303 & 229.917 \\
\hline 16 & 2 & 3 & 1 & 1 & 0.229 & 113.053 & 0.281 & 112.017 \\
\hline 17 & 2 & 3 & 2 & 2 & 0.334 & 195.425 & 0.403 & 200.294 \\
\hline 18 & 2 & 3 & 3 & 3 & 0.416 & 330.114 & 0.522 & 338.873 \\
\hline 19 & 3 & 1 & 1 & 3 & 0.107 & 73.693 & 0.11 & 70.479 \\
\hline 20 & 3 & 1 & 2 & 1 & 0.108 & 93.885 & 0.135 & 97.625 \\
\hline 21 & 3 & 1 & 3 & 2 & 0.126 & 155.628 & 0.133 & 156.614 \\
\hline 22 & 3 & 2 & 1 & 1 & 0.164 & 64.708 & 0.19 & 66.573 \\
\hline 23 & 3 & 2 & 2 & 2 & 0.214 & 154.926 & 0.254 & 150.543 \\
\hline 24 & 3 & 2 & 3 & 3 & 0.326 & 298.575 & 0.39 & 305.566 \\
\hline 25 & 3 & 3 & 1 & 2 & 0.25 & 95.582 & 0.299 & 91.446 \\
\hline 26 & 3 & 3 & 2 & 3 & 0.39 & 240.640 & 0.47 & 243.467 \\
\hline 27 & 3 & 3 & 3 & 1 & 0.305 & 175.715 & 0.371 & 181.420 \\
\hline
\end{tabular}

\section{Experimental Results and Discussions}

Table 3 shows the results of the experiment, including the values of the response factors, surface roughness $(R a)$, cutting force (F). Ra-mql and F-mql, are surface roughness and cutting force, respectively, under MQL cutting condition. Ra-dry and F-dry, are surface roughness and cutting force, respectively, under dry cutting conditions.

ANOVA, a statistical analysis procedure, was used to provide an estimate of the experimental data. The direct and interactive effect of the input factor (cutting-speed, feed-rate, depth-of-cut, and hardness-of-workpiece) on surface roughness and cutting force under MQL- and dry-cutting conditions was analyzed by use of ANOVA. The second-order models for prediction of surface roughness and cutting force under both conditions were established by RSM.

\subsection{The Analysis of Variance and the Mathematical Model of Surface Roughness and Cutting Force under MQL Condition}

The influence of cutting parameters including cutting-speed $(v)$, feed-rate $(f)$, depth-of-cut $(d)$, and hardness-of-workpiece $(h)$ on the surface roughness $(R a-m q l)$ and the cutting-force (F-mql) under MQL conditions was presented by the analysis of variance.

An analysis of the variance of surface roughness under MQL conditions is shown in Table 4. Based on ANOVA, feed-rate and depth-of-cut are the two dominant factors having an influence on surface roughness. These factors contribute $52.76 \%$ and $21.79 \%$ in the total variability of the model, respectively. Otherwise, the effects of cutting-speed, feed-rate, depth-of-cut and hardness on surface roughness are statistically significant with P-value less than 0.05 . 
Table 4. The analysis of variance for experimental values under MQL conditions

\begin{tabular}{|c|c|c|c|c|c|c|}
\hline Source & DF & Adj SS & Adj MS & $\mathbf{F}$ & $\mathbf{P}$ & Cont. \% \\
\hline \multicolumn{7}{|c|}{ ANOVA for Ra-mql, R-Sq = 95.72\% } \\
\hline Model & 14 & 0.186438 & 0.013317 & 19.18 & $0.000^{\mathrm{a}}$ & 95.72 \\
\hline$v$ & 1 & 0.004576 & 0.004576 & 6.59 & $0.025^{\mathrm{a}}$ & 2.35 \\
\hline$f$ & 1 & 0.102756 & 0.102756 & 147.97 & $0.000^{\mathrm{a}}$ & 52.76 \\
\hline$d$ & 1 & 0.042438 & 0.042438 & 61.11 & $0.000^{\mathrm{a}}$ & 21.79 \\
\hline$h$ & 1 & 0.015961 & 0.015961 & 22.98 & $0.000^{\mathrm{a}}$ & 8.19 \\
\hline \multicolumn{7}{|c|}{ ANOVA for $F-m q l, \mathrm{R}-\mathrm{Sq}=98.12 \%$} \\
\hline Model & 14 & 169617 & 12116 & 44.69 & $0.000^{\mathrm{a}}$ & 98,12 \\
\hline$v$ & 1 & 12269 & 12269 & 45.26 & $0.000^{\mathrm{a}}$ & 7,1 \\
\hline$f$ & 1 & 23630 & 23630 & 87.17 & $0.000^{\mathrm{a}}$ & 13,67 \\
\hline$d$ & 1 & 107494 & 107494 & 396.52 & $0.000^{\mathrm{a}}$ & 62,18 \\
\hline$h$ & 1 & 16288 & 16288 & 60.08 & $0.000^{\mathrm{a}}$ & 9,42 \\
\hline
\end{tabular}

${ }^{a}$ Significant

On the other hand, an ANOVA for the cutting force is also shown in Table 4. The cutting force becomes affected primarily by the depth-of-cut followed by feed-rate. The depth-of-cut contributes $62,18 \%$ in the total effect of the factors related to the cutting force. Feed rate's contributions are $13,67 \%$ to the total effect of the factors related to the cutting force. Otherwise, the influences of input factors as cutting-speed, feed-rate, depth-of-cut, and hardness on the cutting force are statistically significant with P-value less than 0.05 .

A mathematical model established using the experiments' results depicts the relationship found between the surface roughness and the cutting parameters under MQL cutting conditions. Using RSM, the roughness Ra model is shown in the following equation (1):

Ra-mql $=1.28831-0.00744864 v-15.8793 f-0.0482593$ $d-0.0404059 h-2.93827 \mathrm{e}-005 v^{\wedge} 2+65.5556 f \wedge 2-$ $0.0194444 d^{\wedge} 2+0.000302222 h^{\wedge} 2+0.156148 v^{*} f-$ $0.00582963 v^{*} d+0.000196148 v^{*} h+7.41111 f^{*} d+$ $0.205778 f^{*} h+0.0106444 d * h$

With a coefficient of determination of the surface roughness model R-sq of $95.72 \%$, it is high and close to 1 , which is deemed to be desirable. Hence, the coefficient of determination expresses that the mathematical model is a suitable model for use in predicting surface roughness under MQL conditions.

The quadratic mathematical model established using the experiments' results is depicted between the cutting force and the cutting parameters under MQL conditions. Using RSM, the cutting-force model is shown in the following equations (2):
$F-m q l=1159-7.65 v+912 f+155 d-44.8 \mathrm{~h}+0.0155$ $v^{*} v-135698 f^{*} f-224 d * d+0.357 h * h-51.6 v * f-4.81$ $v^{*} d+0.1591 v^{*} h+2678 f^{*} d+220.1 f^{*} h+13.80 d^{*} h(2)$

Respectively, the coefficient of determinations R-sq of the cutting force model is $98.12 \%$. It is high and close to 1 , which is deemed to be desirable. Hence, the coefficient of determination expresses that the mathematical model is a suitable model for the prediction of the cutting-force under MQL conditions.

\subsection{The Analysis of Variance and the Mathematical Model of Surface Roughness and Cutting Force under Dry Conditions}

The influence of cutting parameters including cutting-speed $(v)$, feed-rate $(f)$, depth-of-cut $(d)$, and hardness-of-workpiece $(h)$ on the surface roughness (Ra-dry) and the cutting-force under dry conditions was presented by the analysis of variance.

An analysis of variance for surface roughness under dry conditions is shown in Table 5. Based on an analysis of variance, feed-rate and depth-of-cut are considered to be the most influential variables regarding surface roughness. They contribute $56.14 \%$ and $20.88 \%$ to the total effect, respectively. On the other hand, the influences of input factors, such as cutting-speed, feed-rate, depth-of-cut, and hardness-of-workpiece on surface roughness have statistical significance. The surface roughness is affected primarily by the feed-rate variable, followed by depth-of-cut. This finding is similar to the conclusions given by other authors. In research performed by Ahmet, et al. [27], Ilhan, et al. [28], and Kara, F., \& Öztürk, B. [29] the authors concluded that feed-rate is a major factor affecting overall surface roughness 
Table 5. The analysis of variance for experimental values under dry conditions

\begin{tabular}{|c|c|c|c|c|c|c|}
\hline Source & DF & Adj SS & Adj MS & $\mathbf{F}$ & $\mathbf{P}$ & Cont. \% \\
\hline \multicolumn{7}{|c|}{ ANOVA for Ra-dry, $\mathrm{R}-\mathrm{Sq}=95.72 \%$} \\
\hline Model & 14 & 0.304884 & 0.021777 & 19.18 & $0.000^{\mathrm{a}}$ & 95.72 \\
\hline$v$ & 1 & 0.006347 & 0.006347 & 5.59 & $0.036^{\mathrm{a}}$ & 1.99 \\
\hline$f$ & 1 & 0.178802 & 0.178802 & 157.46 & $0.000^{\mathrm{a}}$ & 56.14 \\
\hline$d$ & 1 & 0.066491 & 0.066491 & 58.56 & $0.000^{\mathrm{a}}$ & 20.88 \\
\hline$h$ & 1 & 0.023041 & 0.023041 & 20.29 & $0.001^{\mathrm{a}}$ & 7.23 \\
\hline \multicolumn{7}{|c|}{ ANOVA for $F-d r y, \mathrm{R}-\mathrm{Sq}=97.64 \%$} \\
\hline Model & 14 & 171222 & 12230 & 35.50 & $0.000^{\mathrm{a}}$ & 97.64 \\
\hline$v$ & 1 & 12302 & 12302 & 35.70 & $0.000^{\mathrm{a}}$ & 7,02 \\
\hline$f$ & 1 & 25013 & 25013 & 72.60 & $0.000^{\mathrm{a}}$ & 14,26 \\
\hline$d$ & 1 & 107890 & 107890 & 313.13 & $0.000^{\mathrm{a}}$ & 61,53 \\
\hline$h$ & 1 & 16066 & 16066 & 46.63 & $0.000^{\mathrm{a}}$ & 9,16 \\
\hline
\end{tabular}

a Significant

On the other hand, Table 5 also shows an analysis of variance for the cutting force (F-dry). Cutting force is affected principally by the depth-of-cut followed by feed-rate. Depth-of-cut contributes $61.53 \%$ to the total effect of the factors weighing on cutting force. The contribution of feed-rate is $14.26 \%$ to the total effect of the factors to the cutting force. Taken from another site, the influences of input factors, such as cutting-speed, feed-rate, depth-of-cut, and hardness-of-workpiece have statistical significance on the cutting force. Two main effective factors on cutting forces are the depth-of-cut and the feed-rate (under both MQL and dry conditions). The result can be explained that an increase in both the depth-of-cut and feed-rate will lead to an increased chip-load, thus forming a chip in the shear-zone requiring a larger amount of energy to be expended. So, the removal of material in hard-milling is relatively difficult [24]. The above result is in accordance with conclusions reached by Ding, et al. [9] and Caliskan, et al. [30]. In their studies, Ding, et al. and Caliskan, et al. also presented a similar conclusion stating that the feed-rate and depth-of-cut are two main factors affecting cutting force during the milling process.

A mathematical model established using the experiments' results depicts the relationship between the surface roughness and the cutting parameters under dry cutting conditions. Using RSM, the model is shown in the following equation (3):

$$
\begin{array}{r}
R a-d r y=1.58318-0.00561086 v-20.44 f-0.102333 d- \\
0.0538385 h-4.93827 \mathrm{e}-005 v^{\wedge}+85.5556 f^{\wedge} 2- \\
0.0444444 d^{\wedge} 2+0.000422222 h^{\wedge} 2+0.172889 v^{*} f- \\
0.0072 v^{*} d+0.000204741 v^{*} h+9.78889 f^{*} d+ \\
0.301333 f^{*} h+0.0142667 d^{*} h
\end{array}
$$

With a coefficient of determination of the surface roughness model R-sq of $95.72 \%$, it is high and close to 1 , which is deemed to be desirable. Hence, the coefficient of determination expresses that the mathematical model is a suitable model for predicting surface roughness under dry conditions.

The quadratic mathematical models established using the experiment results depict the relationship between the cutting force and the cutting parameters under dry cutting conditions. Using RSM, the models are shown in the following equations (4):

$$
\begin{gathered}
F-d r y=1219-7.12 v-1767 f+73 d-46.2 h+0.0088 \\
v^{*} v-108844 f^{*} f-221 d^{*} d+0.363 h * h-59.6 v^{*}-3.88 \\
v^{*} d+0.1591 v^{*} h+3933 f^{*} d+257 f^{*} h+13.90 d^{* h}
\end{gathered}
$$

The coefficient of determinations R-sq of the cutting force model is $97.64 \%$. It is high and close to 1 , which is deemed to be desirable. Hence, the coefficient of determination expresses that the mathematical model is a suitable model for predicting the cutting-force under dry conditions.

\subsection{The Comparative Analysis}

Firstly, optimal conditions for surface roughness and cutting-force under both dry and MQL cutting conditions were carried out based on the desirability function. As shown in Figure 2, the cutting-speed of $70 \mathrm{~m} / \mathrm{min}$, feed-rate of $0.01 \mathrm{~mm} /$ tooth, the depth-of-cut of $0.2 \mathrm{~mm}$, and hardness of $40 \mathrm{HRC}$ is the optimal cutting parameters for both conditions dry and MQL. 


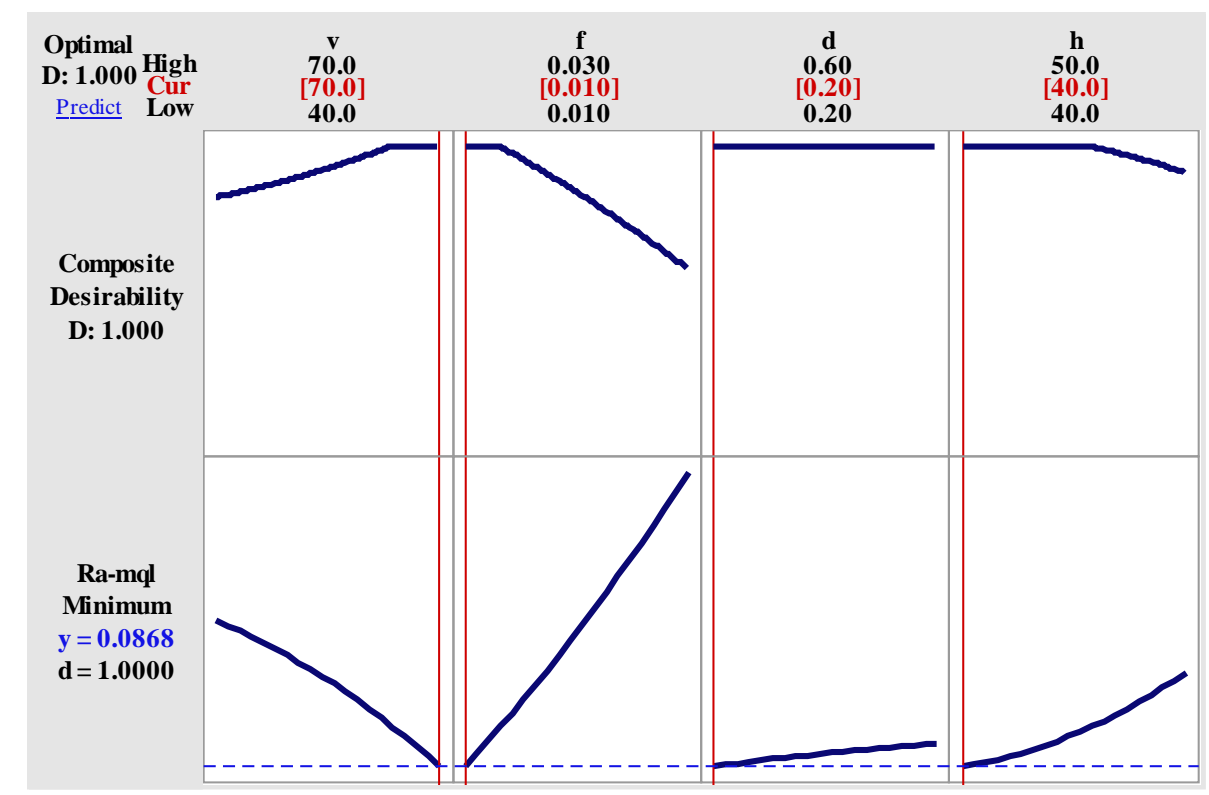

(a)

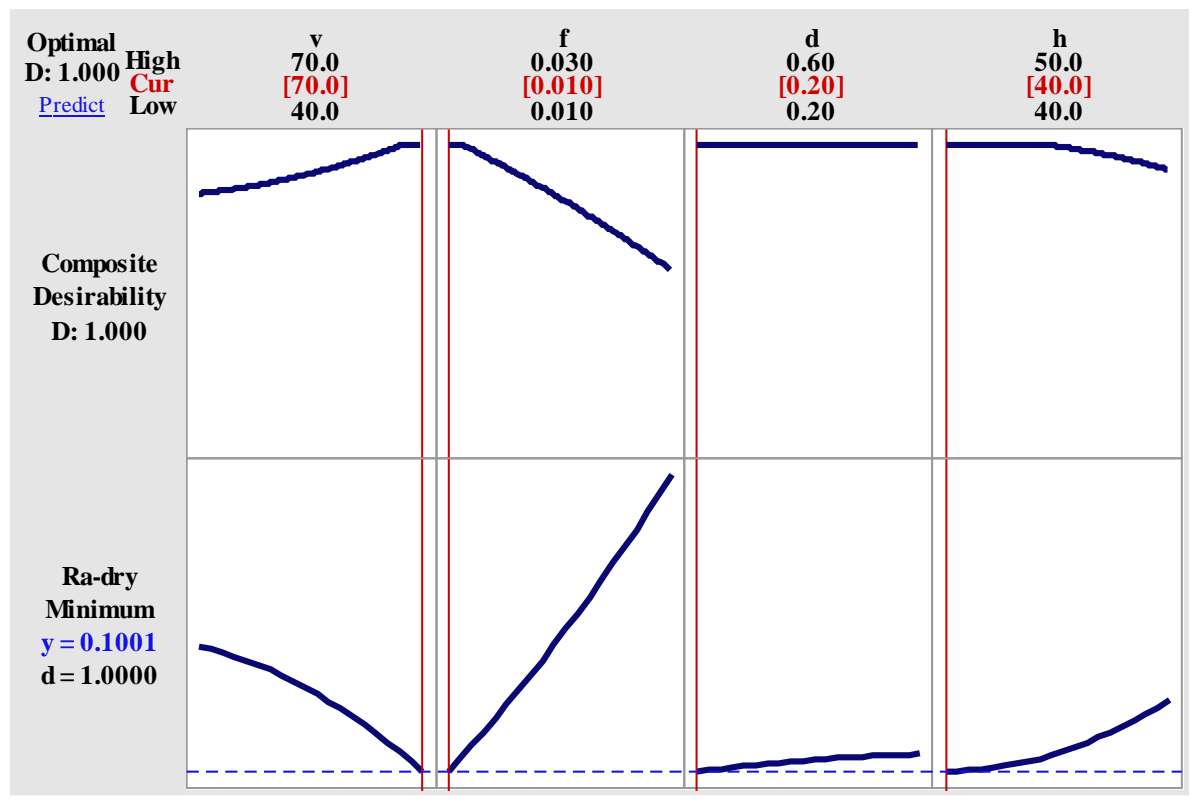

(b)

Figure 2. The optimization plot: (a) The optimization for Ra-mql; and, (b) The optimization for Ra-dry

With these optimal cutting parameters, the predicted minimum surface roughness in the MQL condition $(R a-m q l)$ is $0.0868 \mu \mathrm{m}$, with a desirability value 1.000 as shown in Figure 2(a); and, the minimum surface roughness of the dry condition (Ra-dry) is $0.1001 \mu \mathrm{m}$, with a desirability value 1.000 as shown in Figure 2(b). In both dry and MQL-cutting conditions, a cutting condition including higher cutting-speed, lower feed-rate, lower depth-of-cut, and lower workpiece-hardness will present minimum surface roughness. However, the minimum surface roughness under MQL conditions is considerably less than it is under dry conditions. 


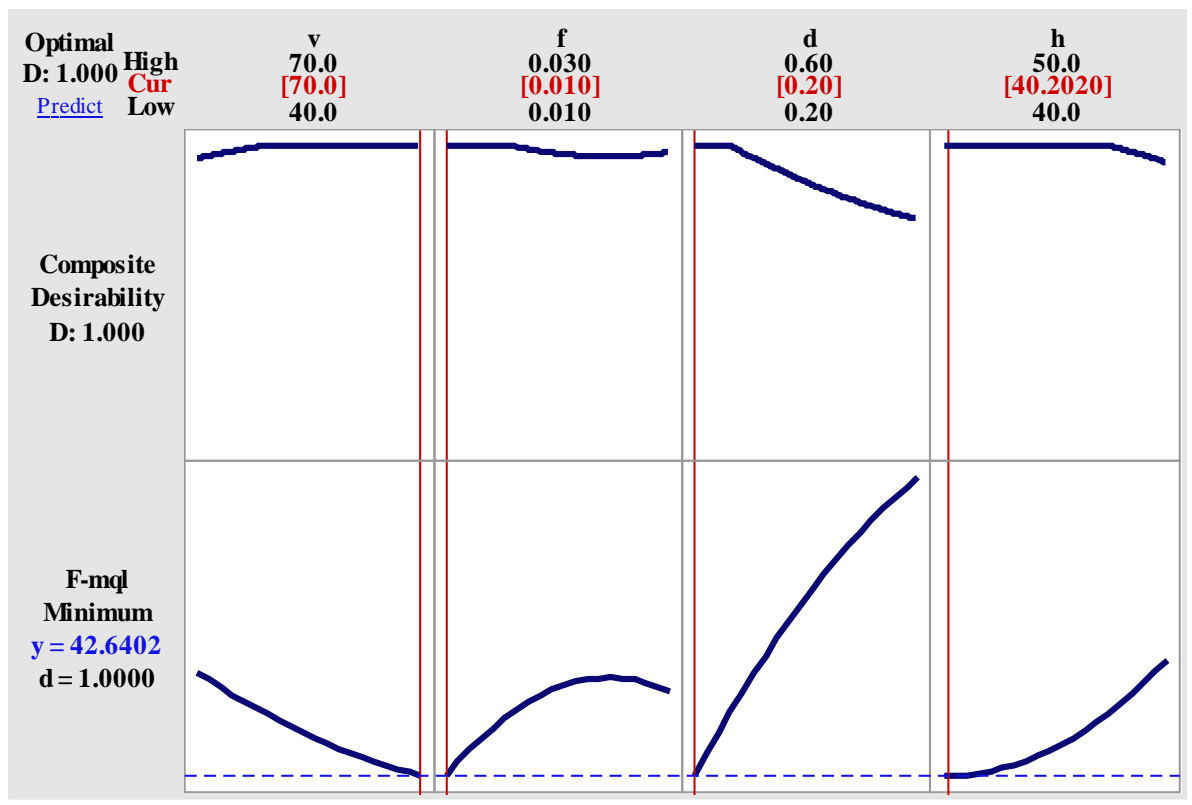

(a)

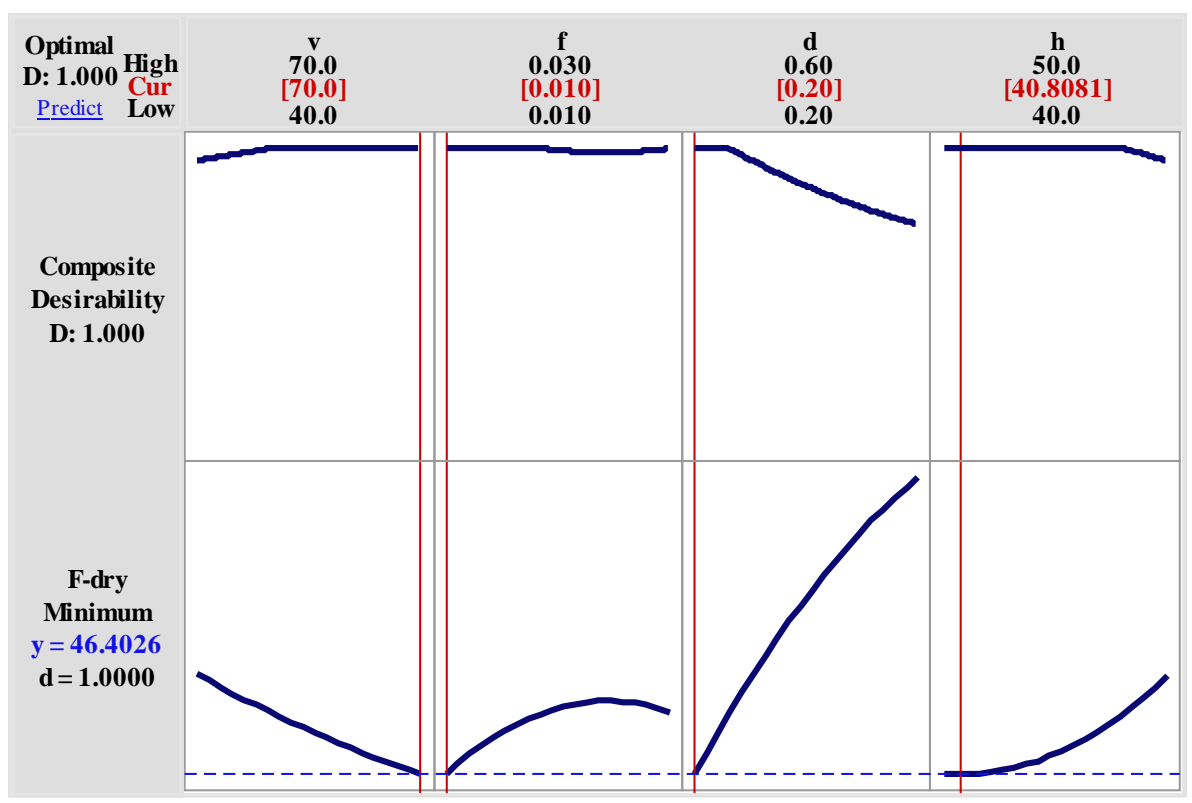

(b)

Figure 3. The optimization plot: (a) The optimization for F-mql; and, (b) The optimization for F-dry.

Figure 3 shows the optimization plot for the cutting force. As shown in Figure 3(a), the cutting-speed of 70 $\mathrm{m} / \mathrm{min}$, the feed-rate of $0.01 \mathrm{~mm} / \mathrm{tooth}$, depth-of-cut of 0.2 $\mathrm{mm}$, and hardness of $40.202 \mathrm{HRC}$ is the optimal cutting parameters under MQL conditions. In dry conditions shown in Figure 3(b), the optimal cutting parameters are $70 \mathrm{~m} / \mathrm{min}$ for the cutting-speed, $0.01 \mathrm{~mm} /$ tooth for the feed-rate, $0.2 \mathrm{~mm}$ in the depth-of-cut, and $40.8081 \mathrm{HRC}$ for workpiece-hardness. With these optimal cutting parameters, in both dry- and MQL-cutting, a higher cutting-speed, lower feed-rate, lower depth-of-cut, and lower workpiece-hardness will present minimum cutting force.
An increase in the amount of cutting-speed produces a reduction in surface roughness. This was reported in some notable research, such as the study by Dureja, et al. [31], Çolak, et al. [32], etc. When machining at low cutting speeds, the formation of a built-up-edge (BUE) on the cutting edge of the tool negatively impacts roughness. Conversely, when machining with higher speeds, the BUE breaks always from the cutting edge lead to improved surface roughness [33]. Additionally, when machining at higher speeds, lower depth-of-cut, and lower feed-rate, the cutting temperature increases in the shear-zone. The material becomes softer and the chip formation is facilitated. Thus, there is an appreciable result in 
improved roughness [34]. The increase of feed-rate is considered to be the main reason causing an increase in surface roughness. It is explained that milling at a higher feed-rate produces deeper and broader furrows on machined surfaces, as reported by Aouici, et al. [35]. The increase of surface roughness due to an acceleration of depth-of-cut and high hardness is clarified inasmuch as this cutting condition provides a chip load which causes an increase in cutting force. A rougher surface is produced by a higher cutting force, as reported by Neto, et al. [36].

Milling with higher speed, lower depth-of-cut, and lower feed-rate results in a lower cutting force requirement [24, 37]. It is explainable in that the effect of increased cutting temperatures causes a thermal softening of the material to occur. The cutting condition consisting of decreases in the feed-rate, depth-of-cut, and workpiece-hardness produces a reduction in the cutting force required. The reason is due to a reduction in chip load; thus, there is only a small amount of energy required to form a chip in the shear- zone. In this way, materials are removed much easier during the milling process.

The comparison of surface roughness is expressed in Figure 4(a). As shown in Figure 4(a), the outstanding effectiveness of MQL when compared to dry cutting was demonstrated. In all of the experimental results produced, the measured Ra values of MQL are less than those found in dry cutting. The improvement of surface roughness in MQL conditions is clarified so that average auxiliary flank wear and notch wear on the auxiliary cutting-edge is obviously reduced under MQL conditions [14, 16, 38]. Moreover, the reduction of surface roughness when applying MQL is due to a decrease in material transfer on o the machined surface area [2].

Shown in Figure 4(b) is the comparison of the real values of the cutting-force. Figure 4(b) shows that the experimental results of cutting force under MQL are closer to those under dry cutting conditions. Therefore, it is demonstrated that a decrease of cutting-force as an effect of increased cutting temperature and thermal softening of materials under dry conditions and a decrease of cutting-force as an effect of reduced friction due to the presence of a lubricant are roughly equal.

Figure 5 shows the variation in cutting-force and surface roughness with machining times under dry and MQL conditions and with the same cutting parameters, including a cutting-speed of $55 \mathrm{~m} / \mathrm{min}$, feed-rate of 0.02 $\mathrm{mm} / \mathrm{teeth}$, depth of $0.6 \mathrm{~mm}$, and hardness of 50HRC. As shown in Figure 5(a), in short machining time, the cutting-force components obtained in MQL condition are equal to those in dry cutting. However, with a longer machining time, the cutting-force components gradually increase over the duration of the cutting time. The growth rate of cutting force components during dry cutting is higher than those of MQL cutting. This is expressed obviously in the duration of machining time greater than 10 minutes. After more than 10 minutes of cutting time, the values of cutting-force of dry cutting are higher than those under MQL conditions. Similarly, as shown in Figure 5(b), with a longer machining time, the growth rate of surface roughness under MQL conditions is lower than with dry cutting. This may be explained by regular tool wear which causes a change in the optimum geometry of the cutting tool originally presented by tool producers. As MQL conditions reduce tool wear, surface roughness and cutting force also grew at a slower pace. Under dry conditions, due to more intensive temperature and stress located at the tool-tips [9], the tool wear deteriorated drastically when compared to MQL. Therefore, effectiveness in reducing tool wear of MQL appeared as a direct result. 


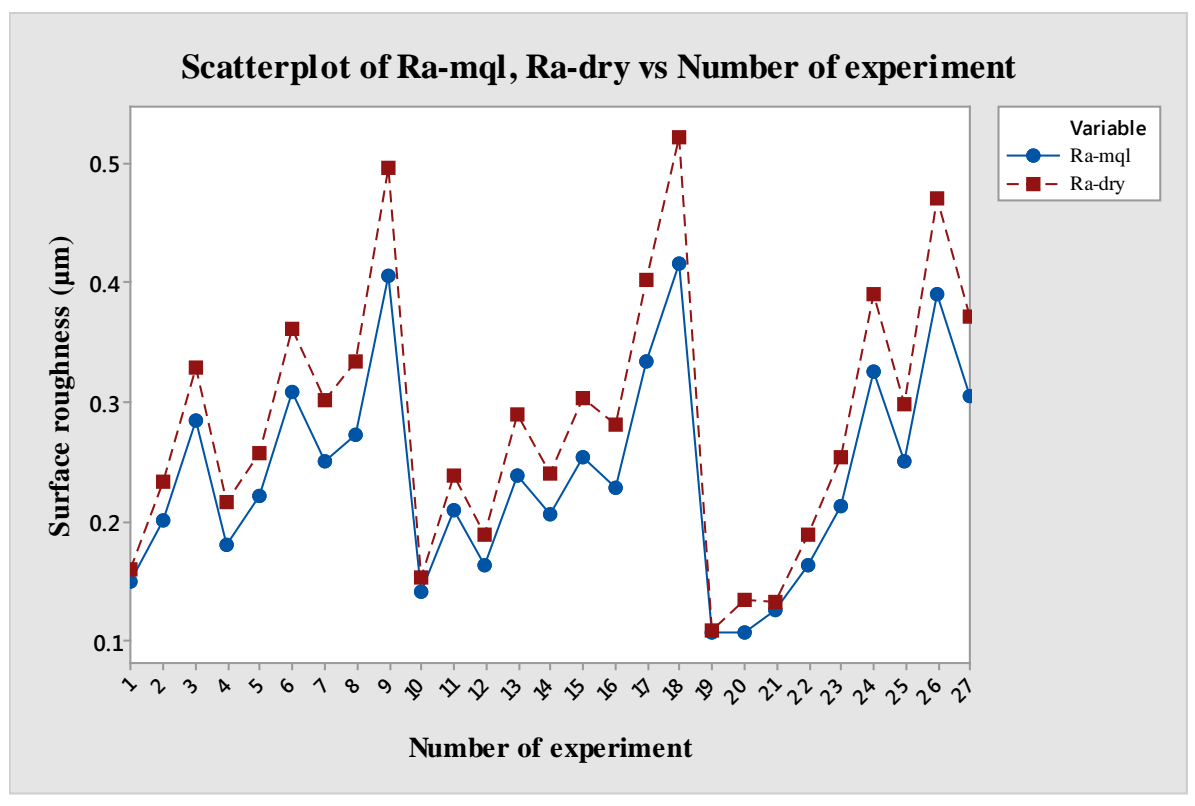

(a)

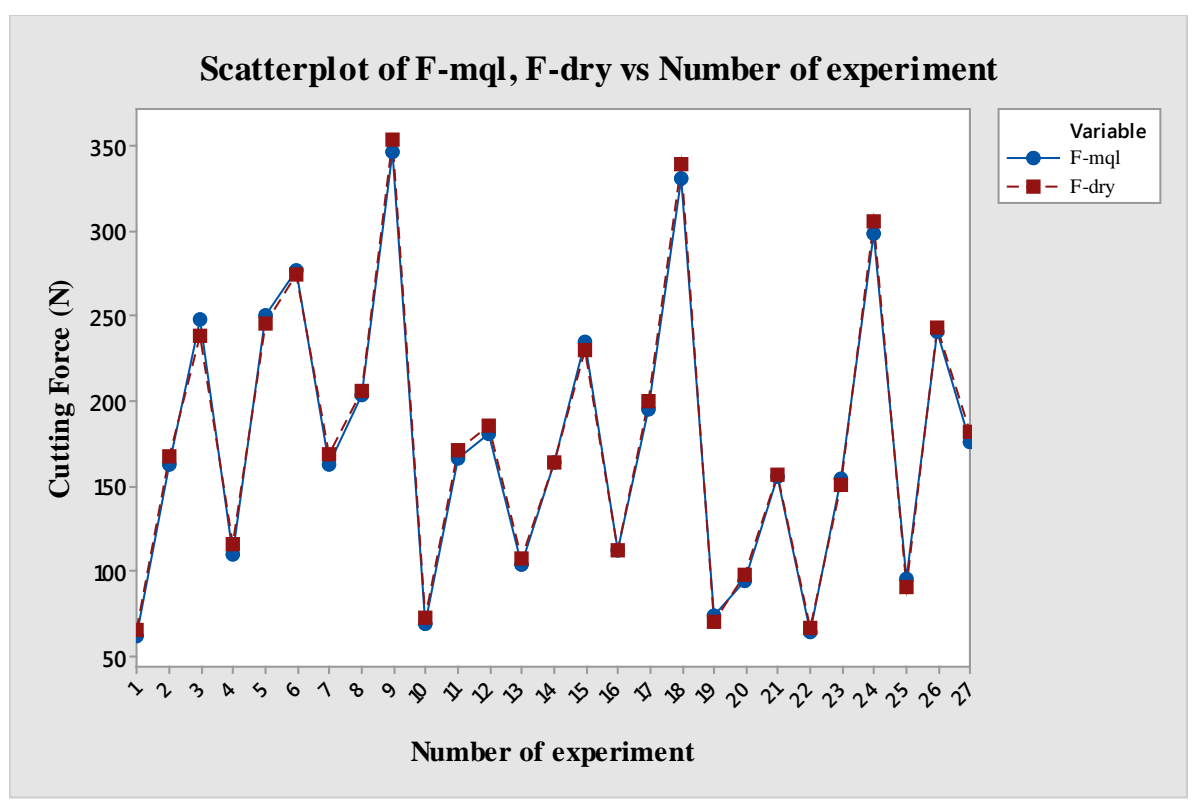

(b)

Figure 4. The comparison of roughness (a) and cutting-force (b) under dry and MQL cutting conditions 


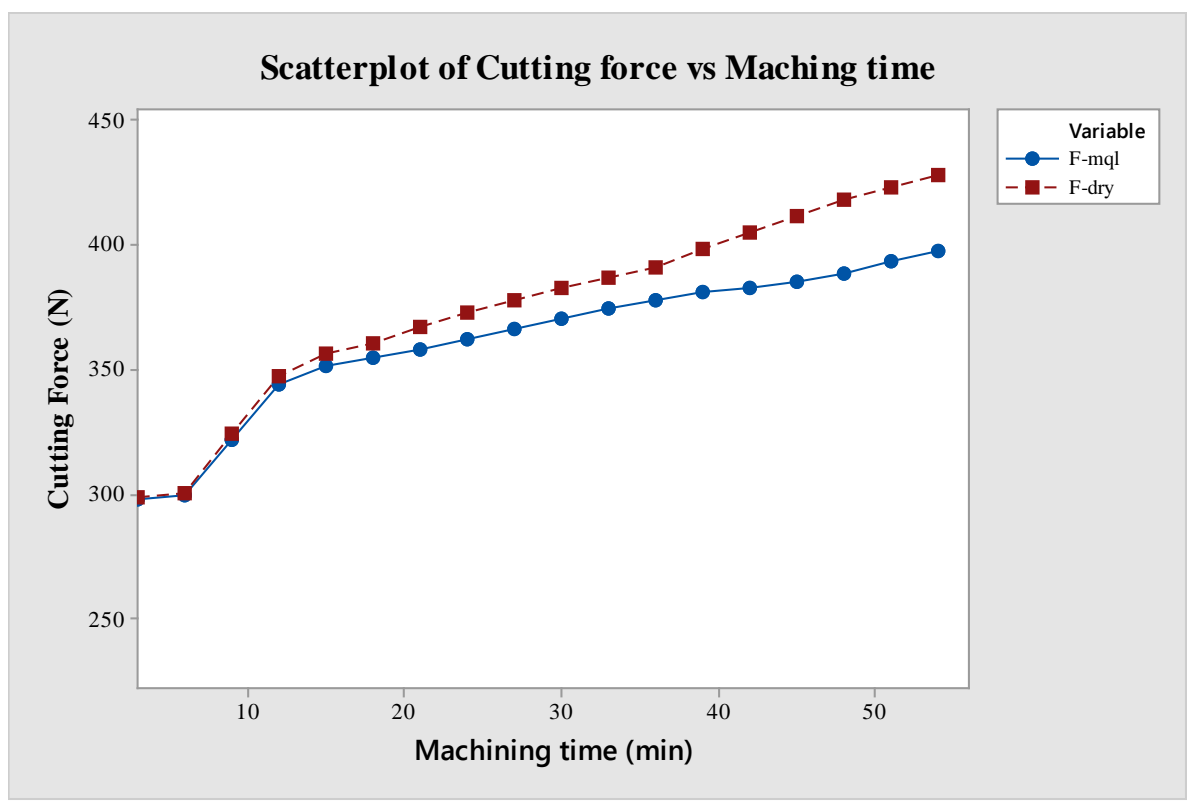

(a)

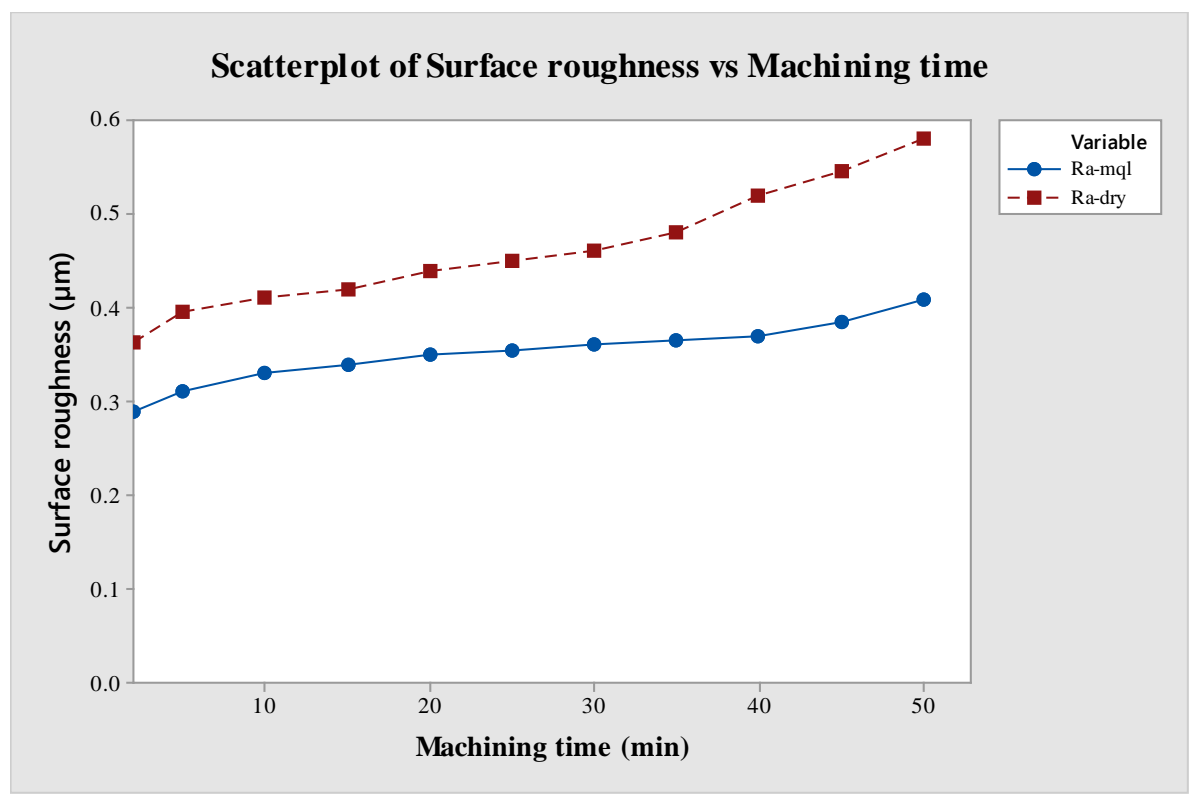

(b)

Figure 5. The comparison of dry and MQL condition in longer machining time

\section{Conclusions}

This study demonstrated the efficiency of MQL when compared to dry cutting based on certain process parameters, such as surface roughness and cutting force during hard-milling of AISI H13 steel. Furthermore, the influence of cutting parameters on the cutting force and the surface roughness under both conditions (MQL and dry) was analyzed. Based on the results of the present study, these conclusions may be drawn:

- Under both of the cutting conditions (MQL and dry), feed rate and depth-of-cut are the main factors affecting surface roughness. The feed rate contributes $52.76 \%$ and depth-of-cut contributes $21.79 \%$ to the total effect under MQL condition. In dry cutting, they contribute $56.14 \%$ and $20.88 \%$ to the total effect, respectively.

- The cutting force is principally affected by depth-of-cut, followed by the feed rate under both MQL and dry conditions. The depth-of-cut contributes $62,18 \%$ and the feed rate's contributions are $13,67 \%$ to the total effect of the factors related to the cutting force under MQL condition. In dry cutting, the depth-of-cut contributes $61.53 \%$ and contribution of feed-rate are $14.26 \%$ to the total effect of the factors to the cutting force. 
- $\quad$ Under both cutting conditions, higher cutting-speed, lower feed-rate, lower depth-of-cut, and lower hardness resulted in good surface roughness and minimum cutting force.

- $\quad$ MQL cutting provided better surface roughness and reduced tool wear. With longer machining times present, the increase of cutting forces resulting from tool wear is lowered with MQL than under dry conditions. Similarly, the growth rate of surface roughness under MQL conditions is lower than with the dry cutting method.

- $\quad$ The linear regression models used for predicting surface roughness and cutting force under dry and MQL conditions are considered to be statistically significant in this study.

\section{REFERENCES}

[1] Sreejith, P. and B. Ngoi, Dry machining: machining of the future. Journal of materials processing technology, 2000. 101(1): p. 287-291.

[2] Sreejith, P., Machining of 6061 aluminium alloy with MQL, dry and flooded lubricant conditions. Materials letters, 2008 62(2): p. 276-278.

[3] Diniz, A.E. and R. Micaroni, Cutting conditions for finish turning process aiming: the use of dry cutting. International Journal of Machine Tools and Manufacture, 2002. 42(8): p. 899-904.

[4] Klocke, F. and G. Eisenblätter, Dry cutting. CIRP Annals-Manufacturing Technology, 1997. 46(2): p. 519-526.

[5] Fuat, K. A. R. A., Optimization of cutting parameters in finishing milling of Hardox 400 steel. International Journal of Analytical, Experimental and Finite Element Analysis (IJAEFEA), 2018. 5(3): 44-49

[6] Popke, H., T. Emmer, and J. Steffenhagen, Environmentally clean metal cutting processes-machining on the way to dry cutting. Proceedings of the Institution of Mechanical Engineers, Part B: Journal of Engineering Manufacture, 1999. 213(3): p. 329-332.

[7] Weinert, K., et al., Dry machining and minimum quantity lubrication. CIRP Annals-Manufacturing Technology, 2004. 53(2): p. 511-537.

[8] Thomas, J., K. Kunte, and V. Arote, Review on machining techniques: dry machining and cryogenic machining. International Journal of Advances Research in Science and Engineering (IJARSE), 2016. 5(2): p. 188-194.

[9] Ding, T., et al., Empirical models and optimal cutting parameters for cutting forces and surface roughness in hard milling of AISI H13 steel. The International Journal of Advanced Manufacturing Technology, 2010. 51(1-4): p. 45-55.

[10] [9] Nelson, S., J. Schueller, and J. Tlusty, Tool wear in milling hardened die steel. Journal of manufacturing science and engineering, 1998. 120(4): p. 669-673.

[11] An, Q., et al., Experimental investigation on hard milling of high strength steel using PVD-AlTiN coated cemented carbide tool. International Journal of Refractory Metals and Hard Materials, 2014. 43: p. 94-101.

[12] Denkena, B., J. Köhler, and B. Bergmann, Development of cutting edge geometries for hard milling operations. CIRP Journal of Manufacturing Science and Technology, 2015. 8: p. 43-52.

[13] Schulz, H. and T. Moriwaki, High-speed machining. CIRP Annals-Manufacturing Technology, 1992. 41(2): p. 637-643.

[14] Dhar, N., M. Kamruzzaman, and M. Ahmed, Effect of minimum quantity lubrication (MQL) on tool wear and surface roughness in turning AISI-4340 steel. Journal of materials processing technology, 2006. 172(2): p. 299-304.

[15] Hwang, Y.K. and C.M. Lee, Surface roughness and cutting force prediction in MQL and wet turning process of AISI 1045 using design of experiments. Journal of Mechanical Science and Technology, 2010. 24(8): p. 1669-1677.

[16] Khan, M., M. Mithu, and N. Dhar, Effects of minimum quantity lubrication on turning AISI 9310 alloy steel using vegetable oil-based cutting fluid. Journal of materials processing Technology, 2009. 209(15): p. 5573-5583.

[17] Dhar, N., et al., The influence of minimum quantity of lubrication (MQL) on cutting temperature, chip and dimensional accuracy in turning AISI-1040 steel. Journal of Materials Processing Technology, 2006. 171(1): p. 93-99.

[18] Kang, M., et al., Effect of the minimum quantity lubrication in high-speed end-milling of AISI D2 cold-worked die steel (62 HRC) by coated carbide tools. Surface and Coatings Technology, 2008. 202(22): p. 5621-5624.

[19] Iqbal, A., N. He, and L. Li. Empirical modeling the effects of cutting parameters in high-speed end milling of hardened AISI D2 under MQL environment. in Proceedings of the World Congress on Engineering, London, UK. 2011.

[20] Duchosal, A., et al., An experimental investigation on oil mist characterization used in MQL milling process. The International Journal of Advanced Manufacturing Technology, 2013. 66(5-8): p. 1003-1014.

[21] Thamizhmanii, S. and S.H. Rosli, A study of minimum quantity lubrication on Inconel 718 steel. Archives of Materials Science and Engineering, 2009. 39(1): p. 38-44.

[22] Rahman, M. and A.S. Kumar, Evaluation of minimal of lubricant in end milling. The International Journal of Advanced Manufacturing Technology, 2001. 18(4): p. 235-241.

[23] Özel, T., T.-K. Hsu, and E. Zeren, Effects of cutting edge geometry, workpiece hardness, feed rate and cutting speed on surface roughness and forces in finish turning of hardened AISI H13 steel. The International Journal of Advanced Manufacturing Technology, 2005. 25(3-4): p. 262-269.

[24] Ghani, J.A., I. Choudhury, and H. Hassan, Application of Taguchi method in the optimization of end milling parameters. Journal of Materials Processing Technology, 2004. 145(1): p. 84-92. 
[25] Nguyen, H.-T. and Q.-C. Hsu, Surface Roughness Analysis in the Hard Milling of JIS SKD61 Alloy Steel. Applied Sciences, 2016. 6(6): p. 172.

[26] Do, T.-V. and Q.-C. Hsu, Optimization of Minimum Quantity Lubricant Conditions and Cutting Parameters in Hard Milling of AISI H13 Steel. Applied Sciences, 2016. 6(3): p. 83.

[27] Hasçalık, A. and U. Çaydaş, Optimization of turning parameters for surface roughness and tool life based on the Taguchi method. The International Journal of Advanced Manufacturing Technology, 2008. 38(9-10): p. 896-903.

[28] Asiltürk, I. and H. Akkuş, Determining the effect of cutting parameters on surface roughness in hard turning using the Taguchi method. Measurement, 2011. 44(9): p. 1697-1704.

[29] Kara, F., \& Öztürk, B., Comparison and optimization of PVD and CVD method on surface roughness and flank wear in hard-machining of DIN 1.2738 mold steel. Sensor Review, 2019. 39(1), p. 24-33.

[30] Çalışkan, H., et al., Investigation of the performance of carbide cutting tools with hard coatings in hard milling based on the response surface methodology. The International Journal of Advanced Manufacturing Technology, 2013. 66(5-8): p. 883-893.

[31] Dureja, J., et al., Design optimization of cutting conditions and analysis of their effect on tool wear and surface roughness during hard turning of AISI-H11 steel with a coated-mixed ceramic tool. Proceedings of the Institution of Mechanical Engineers, Part B: Journal of Engineering Manufacture, 2009. 223(11): p. 1441-1453.

[32] Çolak, O., C. Kurbanoğlu, and M.C. Kayacan, Milling surface roughness prediction using evolutionary programming methods. Materials \& design, 2007. 28(2): p. 657-666.

[33] Jeyakumar, S., K. Marimuthu, and T. Ramachandran, Prediction of cutting force, tool wear and surface roughness of Al6061/SiC composite for end milling operations using RSM. Journal of Mechanical Science and Technology, 2013. 27(9): p. 2813-2822.

[34] Karkalos, N., N. Galanis, and A. Markopoulos, Surface roughness prediction for the milling of Ti-6Al-4V ELI alloy with the use of statistical and soft computing techniques. Measurement, 2016. 90: p. 25-35.

[35] Aouici, H., et al., Machinability investigation in hard turning of AISI D3 cold work steel with ceramic tool using response surface methodology. The International Journal of Advanced Manufacturing Technology, 2014. 73(9-12): p. $1775-1788$.

[36] Neto, H.K., A.E. Diniz, and R. Pederiva, The influence of cutting forces on surface roughness in the milling of curved hardened steel surfaces. The International Journal of Advanced Manufacturing Technology, 2016. 84(5-8): p. 1209-1218.

[37] Bartarya, G. and S.K. Choudhury, Influence of machining parameters on forces and surface roughness during finish hard turning of EN 31 steel. Proceedings of the Institution of Mechanical Engineers, Part B: Journal of Engineering Manufacture, 2014. 228(9): p. 1068-1080.
[38] Paul, S., N. Dhar, and A. Chattopadhyay, Beneficial effects of cryogenic cooling over dry and wet machining on tool wear and surface finish in turning AISI 1060 steel. Journal of Materials Processing Technology, 2001. 116(1): p. 44-48. 